\title{
Renewed and emerging concerns over production and emission of ozone-depleting substances
}

\author{
Martyn P. Chipperfield ${ }^{1 \dagger}$, Ryan Hossaini², Stephen A. Montzka ${ }^{3}$, Stefan Reimann ${ }^{4}$, \\ David Sherry ${ }^{5}$ and Susann Tegtmeier 6
}

1. School of Earth and Environment, University of Leeds, Leeds, UK

2. Lancaster Environment Centre, Lancaster University, Lancaster, UK

3. NOAA Global Monitoring Division, Boulder, CO, USA

4. Empa, Swiss Federal Laboratories for Materials Science and Technology, Dübendorf,

\section{Switzerland}

5. Nolan Sherry Associates (NSA), Kingston, UK

6. Institute of Space and Atmospheric Studies, University of Saskatchewan, Saskatoon, Saskatchewan, Canada

† M.Chipperfield@leeds.ac.uk

- Ozone recovery is expected mid-century owing to adherence to the Montreal Protocol. Yet a number of recent trends could challenge its timely recovery and are highlighted here.

- The apparent illicit production of CFC-11 is one such challenge to ozone recovery, but the added damage to the ozone layer depends on how rapidly the CFC-11 emissions are mitigated.

- A number of industrial processes that are allowed by the Montreal Protocol contribute considerable amounts of chlorinated gas emissions to the atmosphere.

- Increases in ozone-depleting chlorine from a number of human-produced short-lived gases has led to some increased ozone-depletion, although their future impacts on ozone depend on future uses.

- Natural processes also affect the balance of ozone in the stratosphere in a number of ways, and could change in the future as climate responds to increases in atmospheric greenhouse gas concentrations.

Abstract. Stratospheric ozone depletion, first observed in the 1980s, has been caused by the increased production and use of substances such as chlorofluorocarbons (CFCs), halons and other chlorine-containing and bromine-containing compounds, collectively termed ozone- 
depleting substances (ODSs). Following controls on the production of major long-lived ODSs by the Montreal Protocol, the ozone layer is now showing initial signs of recovery, and is anticipated to return to pre-depletion levels in the mid-to-late $21^{\text {st }}$ century, likely $2050-2060$. These return dates assume widespread compliance with the Montreal Protocol and thereby continued reductions in ODS emissions. However, recent observations reveal increasing emissions of some controlled (for example CFC-11, as in eastern China) and uncontrolled substances (for example very short-lived substances, VSLS). Indeed, the emissions of a number of uncontrolled VSLSs are adding significant amounts of ozone-depleting chlorine to the atmosphere. In this Review, we discuss recent emissions of both long-lived ODSs and halogenated VSLSs, and how these might lead to a delay in ozone recovery. Continued improvements in observational tools and modelling approaches are needed to assess these emerging challenges to a timely recovery of the ozone layer.

\section{[H1] Introduction}

The stratospheric ozone layer absorbs harmful ultraviolet (UV) radiation, preventing most from reaching the surface where it can cause skin cancer in humans and damage to plants ${ }^{1}$. Ozone $\left(\mathrm{O}_{3}\right)$ also absorbs outgoing terrestrial infrared radiation in both the stratosphere [G] and troposphere [G], which together with stratospheric heating from UV absorption, exerts a key influence in determining the temperature structure of the atmosphere ${ }^{2}$. Hence, changes in the ozone layer can also affect surface climate, an impact that has been identified in the summertime southern hemisphere ${ }^{3}$ with, for example, a poleward shift of the midlatitude jet ${ }^{4}$. Depletion of the stratospheric ozone layer ${ }^{5,6}$ is therefore a major environmental concern, especially since the discovery of the Antarctic ozone hole in $1985^{7}$. For example, mean column ozone has been depleted by about $50 \%$ in the Antarctic spring and by a maximum of around $4 \%$ decade $^{-1}$ in northern midlatitudes ${ }^{8}$.

63

Ozone depletion is caused by an increased abundance of stratospheric chlorine and bromine ${ }^{8}$, derived from long-lived anthropogenically produced ozone-depleting substances (ODSs) ${ }^{9,10}$, that destroy ozone molecules by converting them to oxygen $\left(\mathrm{O}_{2}\right.$; Fig. 1a). ODSs were used in air conditioning, as refrigerants, solvents and fire-extinguishing agents. To mitigate the damage already caused by ODSs and to prevent further ozone destruction, the Montreal Protocol on Substances that Deplete the Ozone Layer was signed in 1987 and ratified two years later. With several subsequent adjustments and amendments, accepted by almost all countries worldwide, the production and consumption of all of the primary long-lived ODSs such as chlorofluorocarbons (CFCs) and bromine-containing halons - has been controlled [G] and largely stopped through strict phase-out schedules. The latest of these was the phase- 
out of CFCs in 2010. In response, stratospheric levels of chlorine and bromine have slowly declined since their peaks in the $1990 \mathrm{~s}^{11,12}$ (Fig. 1b), primarily due to decreasing concentrations of the controlled substances methyl chloroform $\left(\mathrm{CH}_{3} \mathrm{CCl}_{3}\right)$, CFCs, methyl bromide $\left(\mathrm{CH}_{3} \mathrm{Br}\right)$, and the halons (see Supplementary Information Table $\mathrm{S} 1$ for summary of chemical species, formulae, alternative names and abbreviations).

As a result of the Montreal Protocol, increasing concentrations of stratospheric ozone have been detected in the upper stratosphere ${ }^{13}$ and the Antarctic ${ }^{14-16}$ (Fig. 1C), suggesting that initial stages of recovery are now underway. Multiple processes contribute to the initial recovery observed to date, and separating the influence of the ODS declines to climatechange-related trends is difficult, especially for the Antarctic lower stratosphere ${ }^{17}$. Ozone levels are predicted to return to 1980 concentrations (that is, those prior to any large-scale depletion) around the middle of the $21^{\text {st }}$ century, provided continued compliance with the controls in the Protocol and minimal increases in ozone-depleting halogen levels from uncontrolled sources ${ }^{18-20}$. As such, the Montreal Protocol has been hailed as the most successful international environmental treaty to date.

However, there are many threats to the ongoing success of the treaty and timely recovery of the ozone layer, in particular the increasing emissions of controlled substances that were reportedly phased out and of other chlorinated substances that have never been controlled by the Protocol. Although production of the primary ODSs (CFCs, $\mathrm{CCl}_{4}, \mathrm{CH}_{3} \mathrm{CCl}_{3}$, halons, $\mathrm{CH}_{3} \mathrm{Br}$ ) has largely ceased, recent observations reveal increased emissions of CFC-11, believed to be the result of new production and non-compliance with Montreal Protocol controls ${ }^{21,22}$. Moreover, ODS emissions can persist for various legitimate reasons, including, the escape or use of stocks or banks [G] of ODSs (typically CFCs, HCFCs and halons) produced before the mandated phase-out of production, and inadvertent by-product formation and emission associated with allowed production of controlled substances (including CFCs, HCFCs, and hydrofluorocarbons, or $\mathrm{HFCs}^{23,24}$ ), for example when used solely for non-emissive [G] purposes (such as further chemical manufacture).

Additional chlorine is further reaching the stratosphere from increased production of some uncontrolled [G] very short-lived substances (VSLSs), which are largely removed naturally from the atmosphere in $<0.5$ yrs and have historically been responsible for only a small amount of ozone-depleting bromine and chlorine ${ }^{25}$. Recent observed increases in their concentrations add a new concern to the timely recovery of stratospheric ozone ${ }^{26,27}$. Unlike long-lived ODSs, the short tropospheric lifetimes [G] of VSLSs mean that transport processes determine how efficiently emissions reach the stratosphere. Both VSLS transport and chemical loss rates vary 
111 in space and time, thus their ozone depletion potentials [G] (ODPs) depend on the region and

112 season of emission ${ }^{28-30}$.

114 In this Review, we describe the emission trends of the abundant anthropogenic ODSs,

115 including the recent increase in emissions of CFC-11, likely associated with illicit production,

116 and those of uncontrolled VSLSs. We relate these trends to compliance with the Protocol and

117 discuss possible future variations in ODSs and VSLSs. We then discuss the possible impact

118 on the timescale for ozone recovery.

[H1] Recent observations

123 Independent global-scale air sampling networks maintained by the National Oceanic and

124 Atmospheric Administration (NOAA) and the Advanced Global Atmospheric Gases

125 Experiment (AGAGE) provide measures of the surface abundances of a range of halogenated 126 gases that affect stratospheric ozone. We begin by summarising recent trends in the global 127 concentrations of important controlled and uncontrolled substances as determined by these 128 networks (Fig. 2).

\section{0 [H2] Long-lived controlled ODSs}

131 The chemicals most responsible for ozone layer destruction are a subset of chlorine- and

132 bromine-containing human-produced gases that persist in the atmosphere for decades to 133 centuries after being emitted. These 'long-lived' gases are eventually transported to the 134 stratosphere where they then release their ozone-depleting chlorine and bromine (Fig 1a).

\section{[H3] CFC-113 and methyl chloroform}

137 How an ODS is or was used industrially influences the persistence of its emission after 138 production is phased-out. For example, as CFC-113 and methyl chloroform (Fig. 2a,b) were 139 used as solvents or cleaning agents, emissions occurred mostly during use and there was no 140 build-up of a large bank of produced-but-not-yet-emitted ODSs ${ }^{31}$. Hence, emissions of ODSs 141 used primarily in these applications declined rapidly after production ceased. Global 142 concentrations of methyl chloroform, for instance, decreased by $\sim 18 \% \mathrm{yr}^{-1}$ after 1998 , from 143130 parts per trillion (ppt) in the 1990s to <2 ppt in 2018, indicating near-zero emissions since 144 the year 2000 given its atmospheric lifetime of $5 \mathrm{yrs}\left(\mathrm{REF}^{32}\right)$ (see Supplementary Information 145 for discussion of link between emissions, lifetime and atmospheric abundance). Similar rapid 146 declines in emissions of CFC-113 have also been observed, although its atmospheric 147 abundance has declined much more slowly compared to methyl chloroform given its longer 
148 lifetime of $\sim 93 \mathrm{yrs}\left(\mathrm{REF}^{25}\right)$. Because emissions of chemicals used by humans are largest in

149 the northern hemisphere, concurrent declines in the hemispheric concentration difference

150 further support the implied emission reductions ${ }^{33}$.

\section{2 [H3] CFC-12}

153 By contrast, ODSs that were used as working fluids in refrigeration and air conditioning 154 systems, such as CFC-12 (Fig 2c), accumulated substantial banks before production was phased out. As a result, emissions of these ODSs have declined more slowly due to persistent ongoing emissions from these reservoirs ${ }^{25}$. In addition, CFCs have long lifetimes that also limit the speed of their decrease in the absence of emission. For example, despite its production

158 being phased out in 2010, global concentrations of CFC-12 have decreased by only $0.6 \% \mathrm{yr}^{-}$

1591 in the recent $~ 5$ years, lower than the $1 \% \mathrm{yr}^{-1}$ decline expected based on its $102-\mathrm{yr}_{\text {lifetime }}{ }^{32}$

160 if emissions had ceased. These lower rates of change thereby indicate ongoing CFC-12 161 emissions, presumably from banks in older refrigerators and air conditioners (see 162 Supplementary Information). Northern-southern hemispheric concentration differences also 163 show slow decreases over time, from 6-8 ppt in the late 1990s, to 1 ppt in 2018 (REF ${ }^{25}$ ), 164 consistent with slowly declining emissions.

167 ODSs such as CFC-11 (Fig. 2d) have been used as blowing agents in foam production, 168 resulting in emissions on slow and fast timescales depending on the type of foam produced; 169 ODSs used to produce insulating closed-cell foams become trapped, slowly leaking to the 170 atmosphere, whereas those in open-cell cushioning foams rapidly escape ${ }^{31}$. Therefore, when 171 CFC-11 production began decreasing in 1990, its atmospheric concentrations started to 172 decline shortly thereafter following escape from open-cell foams. However, emissions from 173 the slow-release foams persisted and the concentration decline did not accelerate in 174 subsequent years beyond $-0.8 \% \mathrm{yr}^{-1}$, slower than the limiting decline rate of $-2 \% \mathrm{yr}^{-1}$ expected 175 in the absence of emission given its $~ 50$-yr lifetime. The measured concentration declines 176 suggest that CFC-11 emissions remained constant for the 2002-2012 decade, which was 177 unexpected given that new production of CFC-11 was negligible by 2007 and had reportedly 178 ended by $2010\left(\mathrm{REF}^{21}\right)$. In the absence of new production, emissions from banks should have decreased slowly over time as the closed-cell foam reservoir became depleted.

181 Furthermore, global CFC-11 concentration declines between 2016 and 2018 were only half 182 as fast as those observed between 2002 and 2012 (Fig. 2d), suggesting that emissions had 183 actually increased in recent years. Whereas projections had anticipated CFC-11 reductions of 18414.8 ppt between 2013 and $2018\left(\operatorname{REF}^{34}\right)$, the observed decline was only $\sim 6.7$ ppt (REF ${ }^{21}$ ) 
(Fig. 2d). Even in a scenario in which the global concentration decline had not accelerated as projected after 2013, but had remained constant at a rate of $0.8 \% \mathrm{yr}^{-1}$, the $2018 \mathrm{global}$ surface

187 concentration of CFC-11 was elevated by $\sim 4 \mathrm{ppt}$ (corresponding to $12 \mathrm{pptCl}$ ) relative to $2013^{21}$.

188 These values are substantial when compared with the annual decline in chlorine from all

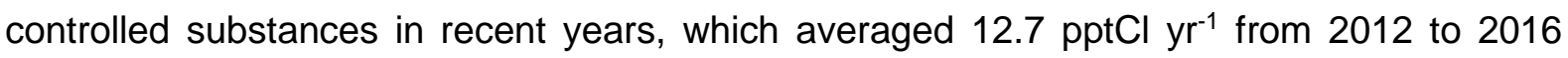

$190\left(\mathrm{REF}^{25}\right)$. In addition, the hemispheric concentration difference increased from 2 ppt to approximately 3 ppt after 2012. Taken together, these observations point to an increase in CFC-11 emissions in the northern hemisphere, likely from new production rather than foam banks, after the 2010 phase-out, in violation of Montreal Protocol controls ${ }^{21,22}$. Results from globally-distributed remote locations suggested that the emission increase stemmed, in part, from eastern Asia ${ }^{21}$. Subsequent measurements from that region further confirmed that approximately half of the global emission increase originated from two industrialised provinces in eastern China, Shandong and Hebei ${ }^{22}$.

Uncertainties in the total amount of newly-produced CFC-11, as well as its application (for example, closed-cell foam versus solvents, the former generating an ODS bank), contribute to an absence of clarity regarding the impact on the ozone layer and its recovery. If the new CFC-11 is used for closed-cell foams, for example, production magnitudes could be up to six times larger ( 78 $\left.\mathrm{Gg} \mathrm{yr}^{-1}\right)$ than the observed emission increase (13 $\left.\mathrm{Gg} \mathrm{yr}^{-1}, \mathrm{REF}^{35}\right)$. The resulting impact on ozone depletion would therefore be much larger than if the new CFC-11 were being used as a solvent or in other applications, thereby implying smaller production and future emission magnitudes and no augmentation of ODS banks.

In addition to this CFC-11 impacting the ozone layer directly, there could have also been CFC12 produced given that both CFCs are typically produced during the fluorination [G] of carbon tetrachloride $^{31}$ (see Supplementary Information for discussion of industrial chlorine processes). This CFC-12, which might be as much as $40 \%$ of the CFC-11 produced, could be intentionally vented or later escape to the atmosphere and exacerbate ozone depletion.

213 However, emissions of CFC-12 do not show signs of substantial increases in recent years

214 either globally (Fig. 2c) or downwind of China ${ }^{22}$. A number of possibilities can explain this 215 apparent absence of increased CFC-12 emissions in the presence of new CFC-11 production: 216 minimal formation of CFC-12 by-product; use of CFC-12 by-product as feedstock for other 217 chemicals without residual emissions; or storage of CFC-12 by-product in closed (slowrelease) applications (refrigeration or air conditioning) ${ }^{21,22}$. of minor controlled CFCs (CFC-13, CFC-113a, CFC-114 and CFC-115) since 2010 (REF $\left.{ }^{24,36}\right)$. 
These can be partly traced to South-East Asia, and while these increases may not represent violations of the Protocol and their concentrations may be low - suggesting minimal risk to ozone depletion - these increases are contrary to the aims of the Montreal Protocol.

\section{[H2] Methyl bromide}

227 Like CFCs, anthropogenic production of methyl bromide $\left(\mathrm{CH}_{3} \mathrm{Br}\right.$; Fig. 2e), a potent ODS, has also declined due to the phase-out of controlled uses in the mid-1990s (REF $\left.{ }^{37,38}\right)$. From a peak of $9.1 \mathrm{ppt}$ in the late 1990s, global mean concentrations decreased $27 \%$ to 6.6 ppt in 2018 $\left(\mathrm{REF}^{25}\right)$. Furthermore, the hemispheric concentration difference decreased from $2.3 \mathrm{ppt}$ in 1996 to 1998 to 0.6 ppt in 2018. However, the 2018 global and southern hemispheric concentrations (6.3 ppt) remain appreciably higher than the natural background southern hemispheric level of $5.5 \pm 0.2$ ppt derived from Antarctic firn-air and ice bubble air ${ }^{25,39,40}$,

234 attributable, in part, to the incomplete phase out of all production for emissive uses by the Montreal Protocol. Specifically, methyl bromide has essential uses that prevent the spread of noxious pests and biota across international boundaries, referred to as quarantine and preshipment (QPS) applications. Today, QPS uses a total of $\sim 10 \mathrm{Gg}$ methyl bromide per year, which has remained relatively constant since the year 2000. However, because QPS is not controlled by the Protocol, any future increase in production for this use would not be a violation of the Montreal Protocol. Other human-related sources, such as rapeseed oil production or farming plants in the Brassica family ${ }^{41}$ are also thought to contribute to the present-day atmospheric concentration, but increases in these sources are thought to be fairly small ${ }^{25}$.

Atmospheric methyl bromide concentrations are sustained today primarily by emissions from natural sources such as biomass burning ${ }^{42}$ and from the ocean. During the 2015-2016 EI Nino, global concentrations of methyl bromide were enhanced by $0.2 \mathrm{ppt}$, likely because of increases in these non-industrial sources. It was the first appreciable increase in global concentration of methyl bromide since the cap on industrial production ${ }^{25}$ and is an important reminder that future variations in its concentration will be determined by how sensitive these natural sources and sinks are to changing temperatures, precipitation, and other climaterelated variables, expected in the future.

\section{[H2] Uncontrolled anthropogenic VSLS}

The Montreal Protocol does not currently control halogenated VSLS, which contributed $3 \%$ of total tropospheric chlorine in $2016\left(\mathrm{REF}^{25}\right)$. As the atmospheric concentrations and ozonedepleting chlorine from two VSLSs have increased substantially in recent years ${ }^{43-45}$, the issue of uncontrolled VSLS emissions has gained increasing recognition. 
261 The most prominent example of a VSLS whose atmospheric concentration has increased

262 recently is dichloromethane $\left(\mathrm{DCM}, \mathrm{CH}_{2} \mathrm{Cl}_{2}\right)\left(\mathrm{REF}^{44}\right)$, which has a mean tropospheric lifetime

263 of $\sim 0.5$ yrs. DCM is used primarily as a solvent in many different applications and is also used

264 in the production of HFC-32 (see Supplementary Information, REF ${ }^{46}$ ). Its global atmospheric abundance has more than doubled since the early 2000s, from an average of $\sim 19$ ppt during 1998 to 2004 to 42 ppt in 2018 (Fig. 2f). This increase has occurred despite the presence of regulations in some regions, including the US and European Union, to reduce the use and emissions of DCM given its suspected carcinogenic properties ${ }^{47}$. Models suggest that about $80 \%$ of the chlorine represented by the global surface mean mixing ratio of DCM enters the stratosphere ${ }^{27}$, implying that DCM contributed nearly $70 \mathrm{pptCl}$ to the stratosphere in 2018 . As the global DCM concentration in 1980 is not well documented, it is difficult to quantify DCM's impact on changes in ozone levels since then. Regardless, the observed 24 ppt DCM increase at the surface since 2000 has led to a chlorine addition to the stratosphere that is only slightly smaller than total $\mathrm{Cl}$ currently contributed by HCFC-141b, and it is nearly twice as large as the current contribution of HCFC-142b, chemicals whose production for dispersive use is currently being phased out globally by the Montreal Protocol.

\section{[H3] Chloroform}

279 Chloroform $\left(\mathrm{CFM}, \mathrm{CHCl}_{3}\right)$ is another VSLS for which the global concentration has increased

280 (by $30 \%$ or $2.5 \mathrm{ppt}$ ) since the late 2000 s, reaching a global mean surface concentration of $\sim 10$ 281 ppt in $2018\left(\mathrm{REF}^{48}\right.$ ) (Fig. 2g). Modelling studies suggest the inferred increase in global $\mathrm{CHCl}_{3}$ emissions between 2010 and 2015 may be almost entirely explained by growth in emissions from China ${ }^{45}$, where it is produced during the industrial manufacture of chloromethanes ${ }^{49}$ (see Supplementary Information), and is an essential component to the production of polytetrafluoroethylene (PTFE), a robust fluoroplastic. Like DCM, chloroform has a mean tropospheric lifetime of around $0.5 \mathrm{yrs}$, with an estimated 2017 stratospheric chlorine contribution of $\sim 17-22 \mathrm{pptCl}$ based on high-altitude aircraft observations and model estimates $^{25,27}$, though the increase since 2010 has only been around $4 \mathrm{pptCl}$. Unlike DCM, natural emissions of chloroform from the terrestrial biosphere are substantial and include emissions from peatlands, tundra, salt marshes and forest soils, among others ( $\left.\operatorname{REF}^{50}\right)$. The ocean has further been suggested as a source for both of these VSLSs ${ }^{51,52}$, but the contribution of this source to total emissions is not well constrained. In the case of chloroform, natural emissions were estimated to account in the early 2000 s for up to $75 \%$ of total global emissions $\left(\mathrm{REF}^{53}\right)$, though a more recent assessment has not been performed. 
297 Other chlorinated VSLSs include perchloroethylene (PCE, $\mathrm{C}_{2} \mathrm{Cl}_{4}$ ), trichloroethylene (TCE, $298 \mathrm{C}_{2} \mathrm{HCl}_{3}$ ), and 1,2-dichloroethane (1,2-DCE, $\mathrm{CH}_{2} \mathrm{ClCH}_{2} \mathrm{Cl}$ ), all of which have predominantly 299 anthropogenic sources. Like other chlorinated VSLS, PCE has found use as both a solvent, 300 for instance in dry-cleaning applications, and as an intermediate in chemical synthesis. Measurements from the NOAA and AGAGE global monitoring networks show a long-term decrease in surface PCE concentration, from 3 ppt in 1995, to 1 ppt in 2018 (REF ${ }^{25,54}$ ). Like PCE, TCE was initially used as an industrial solvent, notably in metal degreasing. TCE solvent usage has also rapidly declined in Europe and North America since being confirmed as a kidney carcinogen ${ }^{55}$, although confirmation of that decrease in atmospheric data is still lacking. Now, TCE is largely used as an intermediate in producing the mobile air-conditioning refrigerant fluid (HFC-134a) (Fig. 2j), which is subject to phase-down in the future provided global ratification of the Montreal Protocol's Kigali Amendment. Today the production and consumption of TCE for both solvent and HFC-134a purposes is known to be large in China ${ }^{56}$. No long-term surface network data for 1,2-DCE are currently available so it is largely unknown whether atmospheric concentrations have changed over time. Nevertheless, a limited set of aircraft measurements show that northern hemisphere boundary layer 1,2-DCE concentrations appear to be $\sim 10-20$ ppt $\left(\mathrm{REF}^{25}\right)$, with this compound contributing $5-15 \mathrm{pptCl}$ to stratospheric chlorine ${ }^{27}$.

\section{[H3] VSLS atmospheric chlorine contribution}

317 The principal VSLS $\left(\mathrm{CH}_{2} \mathrm{Cl}_{2}, \mathrm{CHCl}_{3}, \mathrm{C}_{2} \mathrm{Cl}_{4}, \mathrm{C}_{2} \mathrm{HCl}_{3}, \mathrm{CH}_{2} \mathrm{ClCH}_{2} \mathrm{Cl}\right)$ are estimated to have 318 provided a total of $69(55-83, \pm 1$ standard deviation) $\mathrm{pptCl}$ to the stratosphere in 2000 , 319 increasing to 111 (89-133) pptCl in 2017, based on measured surface concentration changes incorporated into a global model study ${ }^{27}$. This contribution represents $\sim 3.5 \%$ of total stratospheric chlorine. A similar best estimate of 115 (75-160) pptCl for the year 2016 was reported in the $2018 \mathrm{WMO/UNEP} \mathrm{Ozone} \mathrm{Assessment}{ }^{25}$. Both estimates include the chlorine delivered to the stratosphere from the VSLS themselves (source gas injection), accounting for around $80 \%$ of the total, and from the fraction of their degradation products containing chlorine that also reach the stratosphere (product gas injection or PGI). In addition to surface measurements, direct observational evidence for an increase in chlorine source gas injection is also provided by measurements of VSLS (primarily DCM) in the upper troposphere and lower stratosphere over the last two decades ${ }^{57}$. In contrast, surface or aircraft observations alone provide limited means to constrain the magnitude of chlorine PGI, thus the estimated contribution is model-based and includes large uncertainty. This uncertainty arises because the atmospheric concentrations of VSLS degradation products, including hydrogen chloride

$332(\mathrm{HCl})$ and phosgene $\left(\mathrm{COCl}_{2}\right)$, are also products in the oxidation of non-VSLS chlorocarbons. 
333 For example, phosgene is a degradation product of long-lived $\mathrm{CCl}_{4}$ and $\mathrm{CH}_{3} \mathrm{CCl}_{3}$, in addition

334 to several VSLS. Phosgene concentration trends over the $8-30 \mathrm{~km}$ altitude range derived from

335 satellite data, were negative between 2004 and 2016, in keeping with the expectation that

336 phosgene concentrations should decline in response to ongoing decreases in the atmospheric

337 concentration of its long-lived precursors. However, positive phosgene concentration trends

338 have been observed in the upper troposphere, and the sign of this trend is reproduced by

339 global models only when the measured increases in VSLS are considered. Taken together,

340 these observations provide some evidence for an increase in stratospheric chlorine from VSLS

341 degradation products since the mid-2000s ${ }^{58}$.

343 Analysis of ground-based and satellite $\mathrm{HCl}$ measurements are used to evaluate changes in 344 stratospheric inorganic chlorine over time ${ }^{59,60}$; the major source of $\mathrm{HCl}$ is degradation of the 345 long-lived chlorinated ODSs. In the upper stratosphere ( $\geq 10 \mathrm{hPa}, \sim 30 \mathrm{~km})$, measurements 346 from the ACE-FTS instrument show that $\mathrm{HCl}\left(60^{\circ} \mathrm{S}\right.$ to $\left.60^{\circ} \mathrm{N}\right)$ declined at a rate of around $-0.5 \%$ 347 per decade between 2004-201725,61. Over the same period, increases in stratospheric chlorine 348 from VSLS may have slowed the rate of $\mathrm{HCl}$ decline. Fig. 3 compares $\mathrm{HCl}$ trends from a 3-D 349 chemical transport model with and without chlorinated VSLS. It is evident that large interannual 350 dynamical variability confounds $\mathrm{HCl}$ trend analysis, particularly in the lower stratosphere, 351 where trends are most uncertain. In the upper stratosphere, where trends are less influenced 352 by dynamical variability, it is estimated that increases in VSLS reduced the rate of $\mathrm{HCl}$ decline 353 by $\sim 15 \%$ between 2004 and 2017 . This modest offset may partly explain some of the 354 systematic difference between observed $\mathrm{HCl}$ trends and models which do not consider $355 V V_{L S}{ }^{62}$. Furthermore, it implies that anthropogenic VSLS are offsetting some of the benefits 356 of the Montreal Protocol.

357

\section{8 [H2] Natural VSLS}

359 While ozone depletion since the 1980s has been primarily driven by increases in 360 anthropogenic ODSs, short-lived gases emitted from natural sources, especially bromine, also contribute to stratospheric halogen loading and thereby influence stratospheric ozone ${ }^{25,63}$.

363 The most abundant brominated VSLSs are bromoform $\left(\mathrm{CHBr}_{3}\right)$ and dibromomethane

$364\left(\mathrm{CH}_{2} \mathrm{Br}_{2}\right)$, which are largely produced in tropical, subtropical, and shelf regions of the ocean ${ }^{64,65}$ 365 (Fig. 4). However, they do also have some small anthropogenic sources (see section on 366 Bromocarbon Production). Natural production of $\mathrm{CHBr}_{3}$ involves marine organisms such as 367 macroalgae and phytoplankton ${ }^{66}$, while $\mathrm{CH}_{2} \mathrm{Br}_{2}$ is co-formed and its concentration correlates 368 with $\mathrm{CHBr}_{3}$ in water and air ${ }^{67}$. Within the first several months after these VSLSs are emitted to 369 the atmosphere, they can be photochemically oxidised or react with hydroxyl radicals, and 
contribute to the pool of reactive atmospheric bromine ${ }^{68}$. Reactive bromine participates in the depletion of ozone by catalytic cycles and can thus impact tropospheric and stratospheric ozone chemistry.

The ODP-weighted bromine emissions of bromoform (120-820 Gg Br $\mathrm{yr}^{-1}$ ) currently amount to approximately $20 \%\left(\mathrm{REF}^{69}\right)$ of those from total halons and methyl bromide. These estimates carry large uncertainty due to the spatiotemporal variability of VSLS emissions ${ }^{70,71}$, which are driven by changes in primary productivity, biogeochemical cycling, sea surface temperature, and meteorology. Upper atmospheric abundances are similarly heterogeneous, due to the combined effects of highly variable emissions and highly variable atmospheric transport timescales with fastest uplifts in deep convective events ${ }^{72,73}$. A recent update ${ }^{74}$ of the measurement-based bromoform and dibromomethane emission estimates (update of ${ }^{75}$ ) shows enhanced emissions in the tropical Indian Ocean and subtropical northern Atlantic in addition to the known elevated emissions along the coastlines and in upwelling regions (Fig 4). For the west Indian Ocean, updated bromoform emissions are almost twice as large a previous estimates and can reach the stratosphere via two transport pathways; locally through convection and in the south-eastern part of the Asian monsoon anticyclone ${ }^{71}$ highlighting this area as a potentially important source region.

In total, brominated VSLSs_including bromoform and dibromomethane, as well as other minor natural species chlorodibromomethane $\left(\mathrm{CHBr}_{2} \mathrm{Cl}\right)$, bromochloromethane $\left(\mathrm{CH}_{2} \mathrm{BrCl}\right)$ and bromodichloromethane $\left(\mathrm{CHBrCl}_{2}\right.$ ) -are estimated to contribute 5 (uncertainty range 3-7) $\mathrm{pptBr}$ ( 26\%) to stratospheric inorganic bromine $\left(\mathrm{Br}_{\mathrm{y}}\right)$ in $2016\left(\mathrm{REF}^{25,76}\right)$. This range is based on a combination of high-altitude aircraft measurements of source gases around the tropical tropopause and model calculations of bromine product gas injection ${ }^{25,76}$. There is no evidence for a long-term change in this contribution, as variations (an increase followed by current decrease) in total stratospheric bromine have been driven by trends in methyl bromide and halons ${ }^{25}$, with brominated VSLSs providing a constant contribution. While natural brominated VSLS currently have a relatively minor impact on stratospheric ozone compared to anthropogenic halogens, their oceanic production, air-sea fluxes, as well as atmospheric lifetimes and transport pathways are sensitive to climate parameters that may change in the future ${ }^{72,73}$.

In summary, emissions of long-lived ODSs have decreased dramatically over the past few decades due to their phase-out by the Montreal Protocol, leading to unequivocal detection of ozone layer recovery. However, the recently discovered increase in global emissions of CFC11 is a concern. Moreover, some anthropogenic chlorinated VSLS emissions, which together 
contribute around 3\% to stratospheric chlorine and are not subject to the Protocol, are increasing due to industrial production for solvent and feedstock uses. Additionally, the ozone influence of natural sources of bromine contained in short-lived gases, which contributes around $26 \%$ to the current stratospheric bromine loading, is becoming better constrained through increased sampling and improved modelling.

\section{[H1] Current production of ODSs}

415 Despite the successful control of the production of most major ODSs for emissive uses by the 416 Montreal Protocol, chemicals that can deplete ozone are still produced today. Production of 417 ODSs for feedstock use is allowed and uncontrolled shorter-lived species are produced for a 418 variety of purposes (see Supplementary Information).

\section{[H2] Chlorocarbon production}

421 Chlorinated $\mathrm{C}_{1}$ and $\mathrm{C}_{2}$ hydrocarbons are produced extensively, both as chemical intermediates and as solvents for the pharmaceutical and electronics industries as well as in metal and apparel cleaning. Long-lived substances such as carbon tetrachloride (CTC, $\left.\mathrm{CCl}_{4}\right)$ and methyl chloroform (MCF, $\mathrm{CH}_{3} \mathrm{CCl}_{3}$ ) are globally no longer used as solvents, because they are ODSs and have been phased-out under the Montreal Protocol. On-going emissions of uncontrolled, shorter-lived chlorocarbons to the atmosphere are due to fugitive emissions from solvent uses, emissions from production plants (which are inevitable) and feedstock production losses during production of other substances (such as HCFCs and HFCs) (Fig. 5).

430 The group of chlorinated $\mathrm{C}_{1}$ hydrocarbons (chloromethanes) is composed of methyl chloride, $431\left(\mathrm{CH}_{3} \mathrm{Cl}\right)$, DCM $\left(\mathrm{CH}_{2} \mathrm{Cl}_{2}\right)$, chloroform $\left(\mathrm{CHCl}_{3}\right)$ and $\mathrm{CTC}\left(\mathrm{CCl}_{4}\right)$. Methyl chloride is used as a chemical intermediate in the silicone industry and in the production of $\mathrm{CH}_{2} \mathrm{Cl}_{2}, \mathrm{CHCl}_{3}$ and $\mathrm{CCl}_{4}$ in a variety of smaller uses, such as methyl cellulose production. The production of methyl chloride, virtually all by the addition of $\mathrm{HCl}$ to methanol, is usually conducted on the site where it will be processed. Emissions of methyl chloride are negligible compared to its large natural emissions $^{25}$. The chlorination of methyl chloride inevitably produces the higher chloromethanes DCM, chloroform and CTC (Fig. 5). Of the estimated $1162 \mathrm{Gg}$ of DCM produced in $2016,85 \%$ (988 Gg) is calculated to have been emitted by solvent applications (assuming that $100 \%$ of the amount used as solvent is emitted within the year), and $15 \%$ (174 $\mathrm{Gg}$ ) was used as feedstock in the production of HFC-32. By contrast, more than $95 \%$ of the estimated $1472 \mathrm{Gg}$ of chloroform produced in 2016 was consumed as feedstock in the production of HCFC-22, and only $54 \mathrm{Gg}$ emissions arose from solvent uses, most typically

443 from pharmaceutical manufacture. These emissions are considerably smaller than natural 
444

445

446

447

448

449

450

451

452

453

454

455

456

457

458

459

460

461

462

463

464

465

466

467

468

469

470

471

472

473

474

475

476

477

478

479

480

emissions. Until 2010, global emissions were stable at around $300 \mathrm{Gg} \mathrm{yr}^{-1}$ or less. However, in the recent years an increase of around $50 \mathrm{Gg} \mathrm{yr}^{-1}$ has occurred ${ }^{25}$, which could mostly be related to emissions from eastern China ${ }^{45}$. It is unclear if these emissions are due to solvent use or, less likely, emissions from feedstock use.

The estimated $203 \mathrm{Gg}$ of CTC produced in 2016 was, in addition to the co-production from chloromethane plants, also made on-demand in perchloroethylene (PCE)-CTC reactors. Produced amounts were used as feedstock for the production of HFC-245fa, HFC-365mfc, HFO-1233xd, HFO-1234yf, and HFO-1234ze as well as of synthetic pyrethroids such as cypermethrin. An additional important use of CTC is its conversion into PCE. If CTC cannot be consumed by industrial feedstock use, it must be destroyed by permitted processes. It is estimated that most of the CTC produced in 2016 was consumed as feedstock and the balance incinerated, with bottom-up emissions from all sources calculated at $15 \mathrm{Gg}\left(\mathrm{REF}^{77}\right)$.

The group of chlorinated $\mathrm{C}_{2}$ hydrocarbons includes perchloroethylene $\left(\mathrm{PCE}, \mathrm{C}_{2} \mathrm{Cl}_{4}\right.$ ), trichloroethylene (TCE, $\left.\mathrm{C}_{2} \mathrm{HCl}_{3}\right)$, and $\mathrm{MCF}\left(\mathrm{CH}_{3} \mathrm{CCl}_{3}\right)$. Global production of PCE was estimated to be $405 \mathrm{Gg}$ in 2016 (NSA data), of which $200 \mathrm{Gg}$ was used in emissive solvent applications and the balance of $205 \mathrm{Gg}$ being used as chemical intermediate, mainly to CFC113 and CFC-113a and their further derivatives, such as HFC-134a, HFC-125 and chlorotrifluoroethylene (CTFE) monomer. TCE production was estimated at $465 \mathrm{Gg}$ in 2016 (based on Nolan Sherry \& Associates, or NSA, data), with $340 \mathrm{Gg}$ being used as chemical intermediate mainly to HFC-134a, and the balance of $125 \mathrm{Gg}$ being used in emissive solvent applications. MCF is produced in Europe and USA, solely for feedstock use for the production of HCFC-141b, HCFC-142b, and HFC-143a, with an estimated quantity of 95 Gg in 2016 (NSA data), and the related MCF emissions due to these applications are thought to be less than $1 \%$.

In summary, the current (2020) outlook for use of these $C_{1}$ and $C_{2}$ chlorocarbons is as follows. The use of DCM as a solvent (resulting in emissions) is thought to be stable to increasing, and its feedstock use in the production of HFC-32 is also increasing. The small solvent use of CFM is stable to decreasing. Its use as an intermediate in the production of HCFC-22 (used in air conditioners) should see a short-term fall due to restrictions in the Montreal Protocol. In the long-term, usage of CFM will likely increase as the use of HCFC-22 as chemical intermediate is expected grow. CTC is only used as an intermediate, which is increasing due to growing HFO production. MCF production is also growing: use in HFC-143a production is believed to have stopped, but its use in HCFC-142b production is increasing, as HCFC-142b is further processed to vinylidene fluoride-based polymers for electronics. There are different routes to 
produce HCFC-142b without using MCF, such as vinylidene chloride. Solvent use of PCE is

482 thought to be stable to declining, with its feedstock use to HFC-125 and HFC-134a also

483 declining. Finally, both TCE solvent and feedstock uses appear to be declining.

\section{[H2] Bromocarbon production}

486 In addition to their natural origin, brominated VSLSs such as bromoform, which are not controlled by the Montreal Protocol, have various industrial sources such as cooling units, desalination plants, ballast and waste water treatment, and seawater toilets. In order to limit biofouling and minimise the survival of organisms, marine water is normally disinfected when used by industry. Chemical disinfection techniques such as chlorination and ozonisation produce a variety of disinfection by-products with bromoform being the main by-product ${ }^{78}$. The magnitude of bromoform produced during disinfection can vary strongly depending on processing method ${ }^{79}$, application, and chemical water characteristics. When the treated water is released, it will spread in the marine environment and is emitted into the atmosphere ${ }^{80}$. Atmospheric measurements cannot readily distinguish between naturally and industrially produced bromoform, making it difficult to measure large-scale bromine emissions from ballast water and assess their impact on the ozone layer.

498

In treated ship ballast water, an average bromoform concentration of $226 \pm 142 \mu \mathrm{g} \mathrm{L}^{-1}$ can be expected, which is up to a million times higher than abundances found in the natural environment ${ }^{80}$. If all ballast water in the Rotterdam port, for instance, was treated via chlorination and ozonisation, modelling suggests that bromoform concentrations in the inner harbour waters would be up to $0.4 \mathrm{\mu g} \mathrm{L}^{-1}$, which is about 100-1000 times higher than typical near-shore concentrations. However, model-based estimates show that the total bromine emissions from ballast water is likely too small to be important globally ${ }^{80}$.

Bromoform concentrations in treated cooling waters such as power plants with $60 \pm 40 \mu \mathrm{g}$ $\mathrm{CHBr}_{3} \mathrm{~L}^{-1}$ are considerably smaller than in treated ballast water ${ }^{81}$. Despite the smaller concentrations, anthropogenic bromine from industrial cooling water can be expected to be more important, as the total amount of water used is around 200 times larger. For instance, in coastal areas where these cooling waters are dumped, bromoform concentrations range between 0.5 and $50 \mathrm{\mu g} \mathrm{L}^{-1}$ (REFS ${ }^{81,82}$ ). For South-East Asia alone, anthropogenic emissions are on average $24 \mathrm{Gg} \mathrm{Br} \mathrm{yr}^{-1}\left(\mathrm{REF}^{83}\right)$, which is $30 \%$ more than the measurement-based estimate of total emission derived for the same region (18 $\mathrm{Gg} \mathrm{Br} \mathrm{yr}^{-1}$; from $\mathrm{REF}^{74}$, Fig. 4).

516 The final anthropogenic source of brominated VSLS production discussed here is commercial 517 seaweed farming. In Southeast Asia, where substantial amounts of seaweed are cultivated, 
518 current estimates suggest only minor contributions of aquaculture to total VSLS emissions, for

519 example $2 \%$ of bromoform from farmed seaweed compared to natural seaweed in Malaysia ${ }^{84}$.

520 However, projected increases in coastal aquaculture as well as their potential farming in the

521 open ocean in future climate mitigation could substantially increase the brominated VSLS

522 contribution ${ }^{84}$. Thus, potential VSLS emissions from seaweed cultivation should be further

523 investigated for climate change mitigation and food production scenarios that rely on

524 aquaculture.

525

526

527

\section{[H1] Outlook for the future}

528

529

The Montreal Protocol has resulted in decreased ODS emissions and initial recovery of the ozone layer. Given full compliance, and all else being constant, the ozone layer should return to 1980 levels around the mid- $21^{\text {st }}$ century ${ }^{20}$. However, due to the new and renewed concerns associated with ODS production and emission discussed in this Review, the ozone layer might recover at a slower rate than originally anticipated. In this final section, we consider future expected trends in ODS and VSLS emissions and their implications for the timescale of ozone layer recovery.

\section{[H2] Future ODS and VSLS emissions}

538 Future emissions of ODSs will depend on further regulation, compliance, industrial, and environmental factors, making them difficult to predict confidently. However, modelling approaches can provide some insight into what might be expected in the near future, and how these might impact ozone recovery ${ }^{85-87}$. For example, if one of the most concerning ODS trends, the increase in CFC-11 emissions, continues unabated then by 2060 another $180 \mathrm{pptCl}$ would be added to the atmosphere above the amounts expected ( 3000 pptCl; Fig. 1), if all controls in the Montreal Protocol had been followed ${ }^{85}$ (Fig. 6). This extreme scenario, while unlikely, would delay the return of the Antarctic ozone hole to 1980 levels by approximately ten years, to $\sim 2060^{85}$. Similarly, continued chlorinated VSLS emissions (which are allowed under the protocol) could slow the healing of the ozone layer. For instance, eliminating some

548 of the anthropogenic VSLS contributions to stratospheric chlorine would advance the ozone return date by about 1 year for each $17 \mathrm{pptCl}$ reduction compared to business as usual emissions $^{85}$.

552 In addition to non-compliant CFC-11 and uncontrolled VSLS emissions, demand for carbon 553 tetrachloride is expected to increase by well over $50 \%$ by 2025 , in comparison to the $203 \mathrm{Gg}$ 554 produced in $2016\left(\mathrm{REF}^{77,88}\right)$ as more HFOs (which replace many HCFCs and HFCs) are 
produced using CTC as a feedstock. The increased demand will likely lead to higher emissions from this production ${ }^{89}$. Chloroform emissions, as well, could increase with any increased use as feedstock for HCFC-22. Increased emissions of these chlorocarbons would delay the ozone return date in relation to how much enhanced chlorine is delivered to the stratosphere, as discussed above.

561 Finally, future natural ODS emissions and atmospheric transport might be influenced by climate change, though long-term changes are yet to be observed. For example, increases in

563 biomass burning could add to the methyl bromide concentration in the atmosphere. 564 Additionally, ocean acidification, changing sea-ice extent, changing ocean primary production and varying meteorological conditions at the ocean surface could influence production of methyl bromide or brominated VSLS in the ocean and their emissions into the atmosphere ${ }^{90,91}$. Investment in large-scale macroalgae farming could result in increased VSLS emissions, especially if located in the tropics ${ }^{84}$. Climate-driven changes of the tropospheric oxidising capacity would affect lifetimes of $\mathrm{CH}_{3} \mathrm{Br}$ and $\mathrm{VSLS}^{73}$, while dynamical changes would affect the troposphere-stratosphere transport of VSLSs and thus their contribution to the stratospheric halogen budget ${ }^{92}$. The net ozone impact of these possible future changes depends on the sensitivity of these processes to changes in climate, and are largely uncharacterised. The emergence of Earth system models that include accurate representations of comprehensive ocean biogeochemistry and stratospheric chemistry could provide further constraints in coming years, although observationally-derived improvements in our understanding of these systems and their feedbacks are also needed.

\section{[H2] Ensuring timely ozone recovery}

579 It is clear that the phase-out of ODS production has overall been an international success.

580 Also important in ensuring that the ozone layer ultimately recovers, however, was the early detection of newly increased CFC-11 emissions, which was a triumph for atmospheric monitoring because it involved detecting a small slowdown in the atmospheric concentration decline. Furthermore, the existing network enabled an indication of which region was contributing to the unexpected emissions ${ }^{22,93}$, which is information critical for enabling the mitigation of the illicit production. However, there are key research needs that would facilitate a timely recovery of the ozone layer. One such need is improved observational networks and modelling capabilities to monitor and assess progress, as current capabilities, although they have improved greatly in recent years, are still limited in ways that hamper effective and rapid mitigation. This improvement will allow more accurate attribution of atmospheric observations

590 to specific emission locations. Moreover, the anticipated controls on greenhouse gases, in 591 addition to the current ODS controls, will put more demands on compliance monitoring as the 
592 most abundant greenhouse gases have a wider variety of sources, source distributions, and 593 sinks than the ODSs. Such progress can be achieved through ongoing and major 594 enhancements in our scientific capabilities to observe and understand changes in our 595 atmospheric environment, such as better spatially resolved observations and high resolution 596 modelling. Finally, there are specific, immediate needs to determine the location of the 597 increased CFC-11 emissions originating outside of eastern China ${ }^{22}$.

599 Renewed production of a major (class I) ODS, CFC-11, in violation of the Protocol represents 600 a serious challenge to the Montreal Protocol, and adds urgency to addressing the current 601 scientific needs of the international policy community tasked with ensuring recovery of the 602 stratospheric ozone layer. The Protocol's advisory Assessment Panels (Scientific, Technology 603 and Economic, and Environmental Effects) have stepped up to assess the initial discoveries 604 and provide insights into the potential cause(s) for the issue and the underlying economic 605 factors that contributed. In addition, all Parties have publicly expressed interest in the issue 606 being rapidly resolved, and are reconsidering aspects of the Protocol's framework and 607 mechanisms to minimise the risk of further non-compliance. This response is yet another 608 example of the importance of communication between the international science and policy 609 communities for ensuring ozone recovery and, despite the challenges that remain ahead for 610 the ozone layer, continued vigilance by both communities will ensure recovery of the ozone 611 layer without substantial delay. 
615 1. Bais, A. F. et al. Environmental effects of ozone depletion, UV radiation and 616 interactions with climate change: UNEP Environmental Effects Assessment Panel, 617 update 2017. Photochem. Photobiol. Sci. 17, 121-258 (2018).

618 2. Myhre, G. et al. Chapter 8: Anthropogenic and natural radiative forcing. (2013).

619 3. Thompson, D. W. J. \& Solomon, S. Interpretation of recent Southern Hemisphere 620 climate change. Science (80-. ). 296, 895-899 (2002).

621 4. Gillett, N. P. \& Thompson, D. W. J. Simulation of recent Southern Hemisphere climate 622 change. Science (80-. ). 302, 273-275 (2003).

5. Molina, M. J. \& Rowland, F. S. Stratospheric sink for chlorofluoromethanes: chlorine

6. Stolarski, R. S. \& Cicerone, R. J. Stratospheric Chlorine: a Possible Sink for Ozone. Can. J. Chem. 52, 1610-1615 (1974).

627 7. Farman, J. C., Gardiner, B. G. \& Shanklin, J. D. Large losses of total ozone in

8. World Meteorological Organisation (WMO). Scientific Assessment of Ozone Depletion: 2018, Global Ozone Research and Monitoring Project - Report No. 58. (2018).

9. Wofsy, S., McElroy, M. B. \& Yung, Y. L. The chemistry of atmospheric bromine. Geophys. Res. Lett. 2, 215-218 (1975).

10. McElroy, M. B., Salawitch, R. J., Wofsy, S. C. \& Logan, J. A. Reductions of Antarctic ozone due to synergistic interactions of chlorine and bromine. Nature 321, 759-762 (1986).

11. Montzka, S. A. et al. Decline in the tropospheric abundance of halogen from halocarbons: Implications for stratospheric ozone depletion. Science (80-. ). 272, 1318-1322 (1996).

12. Prinn, R. G. et al. History of chemically and radiatively important atmospheric gases

13. Newchurch, M. J. et al. Evidence for slowdown in stratospheric ozone loss: First stage of ozone recovery. J. Geophys. Res. 108, 4507 (2003). 
645

14. Yang, E.-S. et al. First stage of Antarctic ozone recovery. J. Geophys. Res. 113, D20308 (2008).

15. Solomon, S. et al. Emergence of healing in the Antarctic ozone layer. Science (80-. ). 353, 269-274 (2016).

16. Strahan, S. E., Douglass, A. R. \& Damon, M. R. Why Do Antarctic Ozone Recovery Trends Vary? J. Geophys. Res. 124, 8837-8850 (2019).

17. Chipperfield, M. P. et al. Detecting recovery of the stratospheric ozone layer. Nature 549, 211-218 (2017).

18. Eyring, V. et al. Multi-model assessment of stratospheric ozone return dates and ozone recovery in CCMVal-2 models. Atmos. Chem. Phys. 10, 9451-9472 (2010).

19. Oman, L. D. et al. Multimodel assessment of the factors driving stratospheric ozone evolution over the 21st century. J. Geophys. Res. 115, (2010).

20. Dhomse, S. S. et al. Estimates of ozone return dates from Chemistry-Climate Model Initiative simulations. Atmos. Chem. Phys. 18, 8409-8438 (2018).

21. Montzka, S. A. et al. An unexpected and persistent increase in emissions of ozonedepleting CFC-11. Nature 557, 413-417 (2018).

22. Rigby, M. et al. Increase in CFC-11 emissions from eastern China based on atmospheric observations. Nature 569, 546-550 (2019).

23. Schoenenberger, F. et al. First observations, trends, and emissions of HCFC-31 (CH2CIF) in the global atmosphere. Geophys. Res. Lett. 42, 7817-7824 (2015).

24. Vollmer, M. K. et al. Atmospheric histories and emissions of chlorofluorocarbons CFC13, CFC-114 and CFC-115. Atmos. Chem. Phys. 18, 979-1002 (2018).

25. Engel, A., Rigby, M. \& et al. Update on Ozone-Depleting Substances (ODSs) and Other Gases of Interest to the Montreal Protocol. in Scientific Assessment of Ozone Depletion 2018 (World Meteorological Organization, Geneva, Switzerland, 2018).

26. Laube, J. C. \& Engel, A. Contribution of very short-lived organic substances to stratospheric chlorine and bromine in the tropics - a case study. Atmos. Chem. Phys. 8, 7325-7334 (2008).

27. Hossaini, R. et al. Recent Trends in Stratospheric Chlorine from Very Short-Lived Substances. J. Geophys. Res. 124, 2318-2335 (2019).

28. Brioude, J. et al. Variations in ozone depletion potentials of very short-lived substances with season and emission region. Geophys. Res. Lett. 37, 3-7 (2010). 
29. Pisso, I., Haynes, P. H. \& Law, K. S. Emission location dependent ozone depletion potentials for very short-lived halogenated species. Atmos. Chem. Phys. 10, 1202512036 (2010).

30. Claxton, T., Hossaini, R., Wild, O., Chipperfield, M. P. \& Wilson, C. On the Regional and Seasonal Ozone Depletion Potential of Chlorinated Very Short-Lived Substances. Geophys. Res. Lett. 46, 5489-5498 (2019).

31. Technology and Economic Assessment Panel (TEAP. Volume 1: Decision $X X X / 3$ TEAP Task Force Report on Unexpected Emissions of Trichlorofluoromethane (CFC11). 1, (2019).

32. SPARC. Lifetimes of Stratospheric Ozone-Depleting Substances, Their Replacements, and Related Species. (World Climate Research Programme, WCRP15/2013, 2013).

33. Liang, Q. et al. Constraining the carbon tetrachloride ( $\mathrm{CCl} 4)$ budget using its global trend and inter-hemispheric gradient. Geophys. Res. Lett. 41, 5307-5315 (2014).

34. Harris, N. R. P. et al. Scenarios and Information for Policy Makers. in Scientific Assessment of Ozone Depletion (World Meteorological Organization, Geneva, Switzerland, 2014).

35. Ashford, P., Clodic, D., McCulloch, A. \& Kuijpers, L. Emission profiles from the foam and refrigeration sectors comparison with atmospheric concentrations. Part 1: Methodology and data. Int. J. Refrig. 27, 687-700 (2004).

36. Laube, J. C. et al. Newly detected ozone-depleting substances in the atmosphere. Nat. Geosci. 7, 266-269 (2014).

37. Montzka, S. A., Butler, J. H., Hall, B. D., Mondeel, D. J. \& Elkins, J. W. A decline in tropospheric organic bromine. Geophys. Res. Lett. 30, 1-4 (2003).

38. Yvon-Lewis, S. A., Saltzmann, E. S. \& Montzka, S. A. Recent trends in atmospheric methyl bromide: analysis of post-Montreal Protocol variability. Atmos. Chem. Phys. $\mathbf{9}$, 5963-5974 (2009).

39. Butler, J. H. et al. A record of atmospheric halocarbons during the twentieth century from polar firn air. Nature 399, 749-755 (1999).

40. Trudinger, C. M. et al. Atmospheric histories of halocarbons from analysis of Antarctic firn air: Methyl bromide, methyl chloride, chloroform, and dichloromethane. J. Geophys. Res. 109, 1-15 (2004).

41. Rhew, R. C., Miller, B. R., Vollmer, M. K. \& Weiss, R. F. Shrubland fluxes of methyl 
bromide and methyl chloride. J. Geophys. Res. Atmos. 106, 20875-20882 (2001).

42. World Meteorological Organization (WMO). Scientific Assessment of Ozone Depletion: 2010, Global Ozone Research and Monitoring Project - Report No. 52. (2011).

43. Hossaini, R. et al. Growth in stratospheric chlorine from short-lived chemicals not controlled by the Montreal Protocol. Geophys. Res. Lett. 42, 4573-4580 (2015).

44. Hossaini, R. et al. The increasing threat to stratospheric ozone from dichloromethane. Nat. Commun. 8, 15962 (2017).

45. Fang, X. et al. Rapid increase in ozone-depleting chloroform emissions from China. Nat. Geosci. 12, 89-93 (2019).

46. Feng, Y., Bie, P., Wang, Z., Wang, L. \& Zhang, J. Bottom-up anthropogenic dichloromethane emission estimates from China for the period 2005-2016 and predictions of future emissions. Atmos. Environ. 186, 241-247 (2018).

47. Schlosser, P. M., Bale, A. S., Gibbons, C. F., Wilkins, A. \& Cooper, G. S. Human health effects of dichloromethane: Key findings and scientific issues. Environ. Health Perspect. 123, 114-119 (2016).

48. Fang, X. et al. Challenges for the recovery of the ozone layer. Nat. Geosci. 12, 592596 (2019).

49. McCulloch, A. Chloroform in the environment: Occurrence, sources, sinks and effects. Chemosphere 50, 1291-1308 (2003).

50. Simmonds, P. G., Derwent, R. G., Manning, A. J., O’Doherty, S. \& Spain, G. Natural chloroform emissions from the blanket peat bogs in the vicinity of Mace Head, Ireland over a 14-year period. Atmos. Environ. 44, 1284-1291 (2010).

51. Kahlil, M. A. K. et al. Natural emissions of chlorine-containing gases: Reactive Chlorine Emissions Inventory. J. Geophys. Res. 104, 8333-8346 (1999).

52. Ooki, A. \& Yokouchi, Y. Dichloromethane in the Indian Ocean: Evidence for in-situ production in seawater. Mar. Chem. 124, 119-124 (2011).

53. Worton, D. R. et al. 20Th Century Trends and Budget Implications of Chloroform and Related Tri-and Dihalomethanes Inferred From Firn Air. Atmos. Chem. Phys. 6, 28472863 (2006).

54. Simmonds, P. G. et al. Global trends, seasonal cycles, and European emissions of dichloromethane, trichloroethene, and tetrachloroethene from the AGAGE observations at Mace Head, Ireland and Cape Grim, Tasmania. J. Geophys. Res. 
Atmos. 111, 1-19 (2006).

55. Kim, I., Ha, J., Lee, J. H., Yoo, K. mook \& Rho, J. The relationship between the occupational exposure of trichloroethylene and kidney cancer. Ann. Occup. Environ. Med. 26, (2014).

56. Friesen, M. C. et al. Historical occupational trichloroethylene air concentrations based on inspection measurements from Shanghai, China. Ann. Occup. Hyg. 59, 62-78 (2015).

57. Leedham Elvidge, E. C. et al. Increasing concentrations of dichloromethane, $\mathrm{CH} 2 \mathrm{Cl} 2$, inferred from CARIBIC air samples collected 1998-2012. Atmos. Chem. Phys. 15, 1939-1958 (2015).

58. Harrison, J. J., Chipperfield, M. P., Hossaini, R. \& Boone, C. D. Phosgene in the Upper Troposphere and Lower Stratosphere : A Marker for Product Gas Injection Due to Chlorine- Containing Very Short Lived Substances. Geophys. Res. Lett. 46, 10321039 (2018).

59. Rinsland, C. P. et al. Long-term trends of inorganic chlorine from ground-based infrared solar spectra: Past increases and evidence for stabilization. J. Geophys. Res. 108, (2003).

60. Froidevaux, L. et al. Global OZone Chemistry And Related trace gas Data records for the Stratosphere (GOZCARDS): methodology and sample results with a focus on $\mathrm{HCl}, \mathrm{H} 2 \mathrm{O}$, and O3. Atmos. Chem. Phys. 15, 10471-10507 (2015).

61. Bernath, P. \& Fernando, A. M. Trends in stratospheric $\mathrm{HCl}$ from the ACE satellite mission. J. Quant. Spectrosc. Radiat. Transf. 217, 126-129 (2018).

62. Froidevaux, L., Kinnison, D. E., Wang, R., Anderson, J. \& Fuller, R. A. Evaluation of CESM1 (WACCM) free-running and specified dynamics atmospheric composition simulations using global multispecies satellite data records. Atmos. Chem. Phys. 19, 4783-4821 (2019).

63. Dorf, M. et al. Balloon-borne stratospheric BrO measurements: Comparison with Envisat/SCIAMACHY BrO limb profiles. Atmos. Chem. Phys. 6, (2006).

64. Quack, B. \& Wallace, D. W. R. Air-sea flux of bromoform: Controls, rates, and implications. Global Biogeochem. Cycles 17, (2003).

65. Butler, J. H. et al. Oceanic distributions and emissions of short-lived halocarbons. Global Biogeochem. Cycles 21, 1-11 (2007).

66. Gschwend, P. M., MacFarlane, J. K. \& Newman, K. A. Volatile halogenated organic 
compounds released to seawater from temperate marine macroalgae. Science (80-. ). 227, 1033-1035 (1985).

778

67. Carpenter, L. J. \& Liss, P. S. On temperate sources of bromoform and other reactive organic bromine gases. J. Geophys. Res. Atmos. 105, 20539-20547 (2000).

68. von Glasow, R. Sun, sea and ozone destruction. Nature 453, 1195-1196 (2008).

69. Tegtmeier, S. et al. Oceanic bromoform emissions weighted by their ozone depletion potential. Atmos. Chem. Phys. 15, 13647-13663 (2015).

70. Fuhlbrügge, S. et al. The contribution of oceanic halocarbons to marine and free troposphere air over the tropical West Pacific. Atmos. Chem. Phys. 16, 7569-7585 (2016).

71. Fiehn, A. et al. Delivery of halogenated very short-lived substances from the west Indian Ocean to the stratosphere during the Asian summer monsoon. Atmos. Chem. Phys. 17, 6723-6741 (2017).

72. Aschmann, J., Sinnhuber, B.-M., Chipperfield, M. P. \& Hossaini, R. Impact of deep convection and dehydration on bromine loading in the upper troposphere and lower stratosphere. Atmos. Chem. Phys. 11, 2671-2687 (2011).

73. Hossaini, R. et al. Modelling future changes to the stratospheric source gas injection of biogenic bromocarbons. Geophys. Res. Lett. 39, L20813 (2012).

74. Fiehn, A., Quack, B., Stemmler, I., Ziska, F. \& Krüger, K. Importance of seasonally resolved oceanic emissions for bromoform delivery from the tropical Indian Ocean and west Pacific to the stratosphere. Atmos. Chem. Phys. 18, 11973-11990 (2018).

75. Ziska, F. et al. Global sea-to-air flux climatology for bromoform, dibromomethane and methyl iodide. Atmos. Chem. Phys. 13, 8915-8934 (2013).

76. Wales, P. A. et al. Stratospheric Injection of Brominated Very Short-Lived Substances: Aircraft Observations in the Western Pacific and Representation in Global Models. J. Geophys. Res. 123, 5690-5719 (2018).

77. Sherry, D., McCulloch, A., Liang, Q., Reimann, S. \& Newman, P. A. Current sources of carbon tetrachloride (CCl4) in our atmosphere. Environ. Res. Lett. 13, (2018).

78. Delacroix, S., Vogelsang, C., Tobiesen, A. \& Liltved, H. Disinfection by-products and ecotoxicity of ballast water after oxidative treatment - Results and experiences from seven years of full-scale testing of ballast water management systems. Mar. Pollut. Bull. 73, 24-36 (2013).

79. Liu, Z. et al. Removing of disinfection by-product precursors from surface water by 
using magnetic graphene oxide. PLoS One 10, (2015).

80. Maas, J. et al. Simulating the spread of disinfection by-products and anthropogenic bromoform emissions from ballast water discharge in Southeast Asia. Ocean Sci. 15, 891-904 (2019).

81. Yang, J. S. Bromoform in the effluents of a nuclear power plant: A potential tracer of coastal water masses. Hydrobiologia 464, 99-105 (2001).

82. Boudjellaba, D., Dron, J., Revenko, G., Démelas, C. \& Boudenne, J. L. Chlorination by-product concentration levels in seawater and fish of an industrialised bay (Gulf of Fos, France) exposed to multiple chlorinated effluents. Sci. Total Environ. 541, 391399 (2016).

83. Maas, J. et al. Simulations of anthropogenic bromoform reveal high emissions at the

84. Leedham, E. C. et al. Emission of atmospherically significant halocarbons by naturally occurring and farmed tropical macroalgae. Biogeosciences 10, 3615-3633 (2013).

85. Dhomse, S. S. et al. Delay in recovery of the Antarctic ozone hole from unexpected CFC-11 emissions. Nat. Commun. 10, 5781 (2019).

86. Dameris, M., Jöckel, P. \& Nützel, M. Possible implications of enhanced chlorofluorocarbon-11 concentrations on ozone. Atmos. Chem. Phys. 19, 13759-

87. Fleming, E. L., Newman, P. A., Liang, Q. \& Daniel, J. S. The Impact of Continuing CFC - 11 Emissions on Stratospheric Ozone. J. Geophys Res. 125, e2019JD038149

88. SPARC. SPARC Report on the Mystery of Carbon Tetrachloride. (World Climate

89. NSA. Carbon tetrachloride 2016-2025: Long, balanced or tightening? The impact of HFOs. (2016).

90. Falk, S. et al. Brominated VSLS and their influence on ozone under a changing climate. Atmos. Chem. Phys. 17, 11313-11329 (2017).

837 91. Ziska, F., Quack, B., Tegtmeier, S., Stemmler, I. \& Krüger, K. Future emissions of marine halogenated very-short lived substances under climate change. J. Atmos. Chem. 74, 245-260 (2017).

840 92. Dessens, O., Zeng, G., Warwick, N. \& Pyle, J. Short-lived bromine compounds in the 
841

842

843

844

845

846

847

848

849

850

851

852

853

854

855

856

857

858

859

860

861

862

863

864

865

866

867

868

869

870

871

872

lower stratosphere; impact of climate change on ozone. Atmos. Sci. Lett. 10, 201-206 (2009).

93. Reimann, S. et al. Observing the atmospheric evolution of ozone-depleting substances. Comptes Rendus - Geosci. 350, 384-392 (2018).

94. Carpenter, L. et al. Scenarios and Information for Policy Makers Chapter 6 in Scientific Assessment of Ozone Depletion: 2018. in Scientific Assessment of Ozone Depletion (2018).

95. Chipperfield, M. P. New version of the TOMCAT/SLIMCAT off-line chemical transport model: Intercomparison of stratospheric tracer experiments. Q. J. R. Meteorol. Soc. 132, 1179-1203 (2006).

96. World Meteorological Organization (WMO). Scientific Assessment of Ozone Depletion: 2014, Global Ozone Research and Monitoring Project - Report No. 55. (2014).

97. Mahieu, E. et al. Recent Northern Hemisphere stratospheric $\mathrm{HCl}$ increase due to atmospheric circulation changes. Nature 515, 104-107 (2014).

98. Chipperfield, M. P. et al. On the Cause of Recent Variations in Lower Stratospheric Ozone. Geophys. Res. Lett. 45, 5718-5726 (2018).

99. Chipperfield, M. P. et al. Quantifying the ozone and ultraviolet benefits already achieved by the Montreal Protocol. Nat. Commun. 6, 7233 (2015).

\section{Related links}

Advanced Global Atmospheric Gases Experiment (AGAGE) monitoring network: https://agage.mit.edu/

National Aeronautics and Space Administration Ozone Watch: https://ozonewatch.gsfc.nasa.gov/

National Oceanic and Atmospheric Administration Earth System Research Laboratory monitoring network: https://www.esrl.noaa.gov/gmd/

United Nations Environment Programme. https://www.unenvironment.org/

United Nations Environment Programme Ozone Country Data. https://ozone.unep.org/countries/data-table

World Meteorological Organization and United Nations Environment Programme Ozone Assessments. https://www.esrl.noaa.gov/csd/assessments/ozone/ 
873 Acknowledgements

874 The authors thank S. Dhomse (University of Leeds) for the data provided in Figure 6. MPC

875 and RH acknowledge support through the NERC SISLAC grant (NE/R001782/1).

876

877 Author contributions

878 All authors contributed to all aspects of the article.

879

880 Competing Interests

881 The authors declare no competing interests.

882

883 Publisher's note: Springer Nature remains neutral with regard to jurisdictional claims in 884 published maps and institutional affiliations.

885

886 Peer review information

887 Nature Reviews Earth \& Environment thanks [Referee\#1 name], [Referee\#2 name] and 888 [Referee\#3 name] for their contribution to the peer review of this work.

\section{Publisher's note}

890 Springer Nature remains neutral with regard to jurisdictional claims in published maps and 891 institutional affiliations.

892 Supplementary information

893 Supplementary information is available for this paper at https://doi.org/10.1038/s415XX-XXX-

894 XXXX-X

895

896 


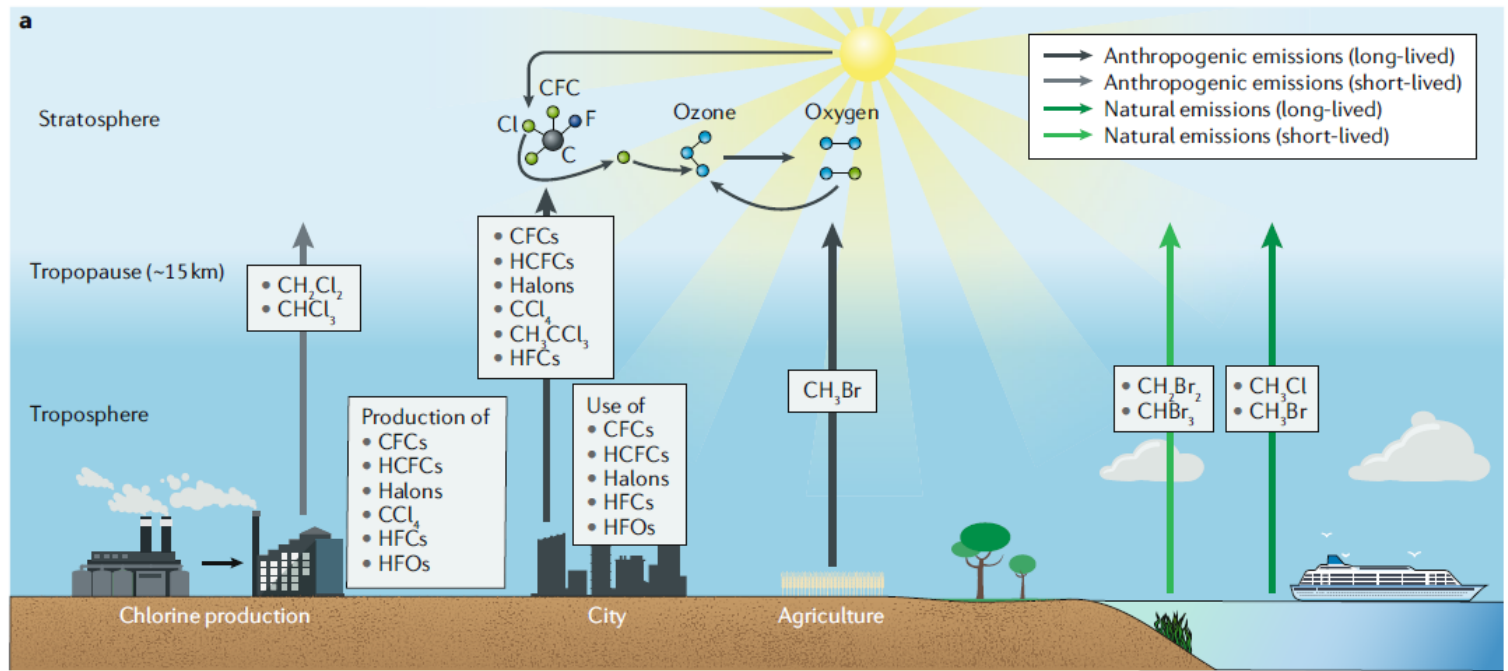

899 Figure 1. Halogenated source gases and their impact on stratospheric ozone. a|

900 Anthropogenic (black and grey arrows) and natural (green arrows) sources of long-lived and

901 short-lived ozone depleting substances. The majority of long-lived Ozone Depleting

902 Substances (ODSs) reach the stratosphere, where they are photochemically decomposed,

903 liberating halogens that destroy ozone $\left(\mathrm{O}_{3}\right)$. Short-lived substances largely decompose in the 904 troposphere and only a fraction of the emissions reaches the stratosphere. $\mathbf{b} \mid$ Past 905 observations and projections of equivalent effective chlorine $(\mathrm{EECl}$; total chlorine $+65 \times$ total 906 bromine at surface, ppb) from different long-lived ODSs between 1960 and 2100. After the 907 signing of the Montreal Protocol and subsequent phase-out of many long-lived ODSs, EECI 908 began to decline and is expected to return to 1980 levels by around 2050, as indicated by the 909 horizontal and vertical dashed lines. c| Measured (red line) and predicted (black line, with 910 uncertainty shown as grey shading) for Antarctic October column ozone (Dobson Units; DU) 911 between 1960 and 2100. The Antarctic ozone layer is expected to return to 1980 levels around 912 2060, around a decade later than EECl (horizontal and vertical dashed lines). 

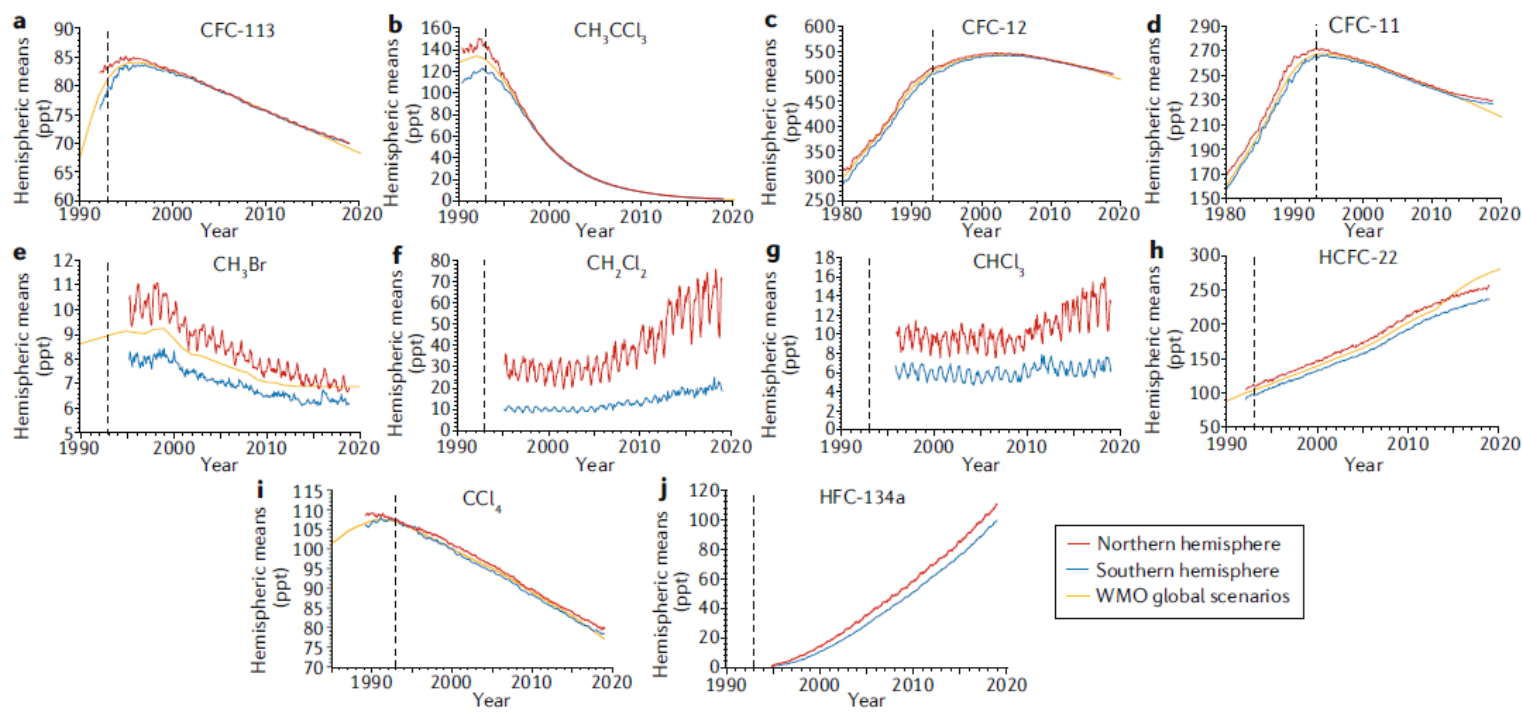

$$
\begin{aligned}
& \text { - Northern hemisphere } \\
& \text { - Southern hemisphere } \\
& \text { - WMO global scenarios }
\end{aligned}
$$

915 Figure 2. Atmospheric concentrations of selected halogenated gases over time.

916 Hemispheric mean concentrations (or mole fractions, as parts per trillion, or ppt; northern

917 hemisphere in red, southern hemisphere in blue) of long-lived ozone-depleting substances

918 (ODSs; a-e, h, i), two very short-lived substances (VSLS; $f, g$ ), and a substitute HFC (j). a-j|

919 CFC-113, methyl chloroform $\left(\mathrm{CH}_{3} \mathrm{CCl}_{3}\right)$, CFC-12, CFC-11, methyl bromide $\left(\mathrm{CH}_{3} \mathrm{Br}\right)$, 920 dichloromethane (DCM, $\left.\mathrm{CH}_{2} \mathrm{Cl}_{2}\right)$, chloroform $\left(\mathrm{CHCl}_{3}\right)$, $\mathrm{HCFC}-22$, carbon tetrachloride $\left(\mathrm{CCl}_{4}\right)$,

921 and HFC-134a concentrations through time. All surface means are derived from NOAA 922 measurements at 4 to 12 remote sites using in-situ and flask collection techniques ${ }^{11,27,44}$.

923 These results, along with those from an independent global network ${ }^{12}$, form the basis for WMO

924 scenario records of global concentration changes for Montreal Protocol-controlled substances

925 for years prior to 2014 (yellow lines on long-lived ODS panels; REF ${ }^{34}$ ). These scenario results 926 are projected into the future based on historical data for production, emissions, and bank 927 reservoirs, and existing production controls. Although an updated scenario analysis is 928 available ${ }^{94}$, the older scenario is used here to understand observed vs expected concentration 929 changes since 2014. The year that tropospheric chlorine from long-lived ozone-depleting 930 gases peaked ${ }^{11}$ (dashed black line) is provided for reference given that the time-scale differs 931 in the panels. Most ODSs are decreasing over time due to phase out. However, the very short932 lived species, DCM and chloroform, both increased during this time period, as did HCFC-22. 
a $\mathrm{HCl}$ trend $\left(60^{\circ} \mathrm{S}-60^{\circ} \mathrm{N}\right)$

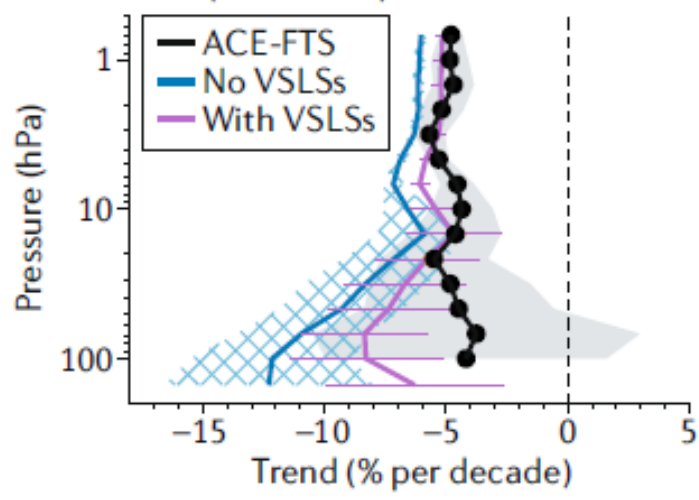

c $\mathrm{HCl}$ trend $\left(30^{\circ} \mathrm{N}-60^{\circ} \mathrm{N}\right)$

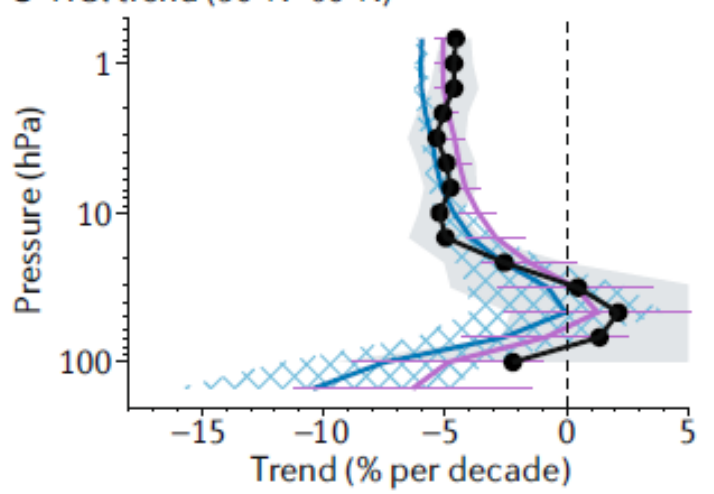

b $\mathrm{HCl}$ trend $\left(30^{\circ} \mathrm{S}-30^{\circ} \mathrm{N}\right)$

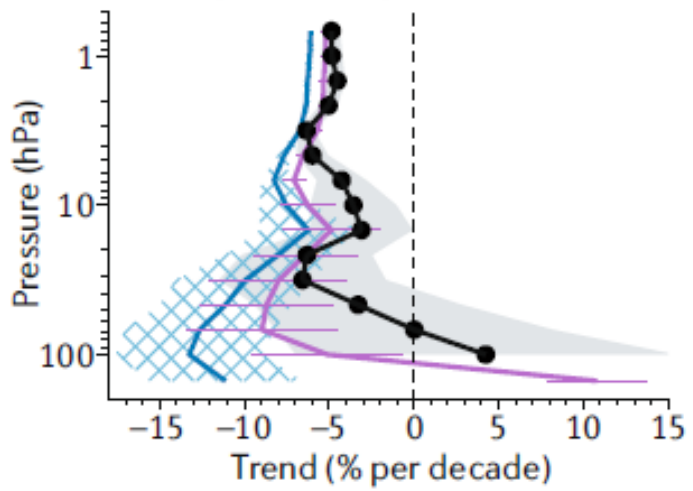

d $\mathrm{HCl}$ trend $\left(30^{\circ} \mathrm{S}-60^{\circ} \mathrm{S}\right)$

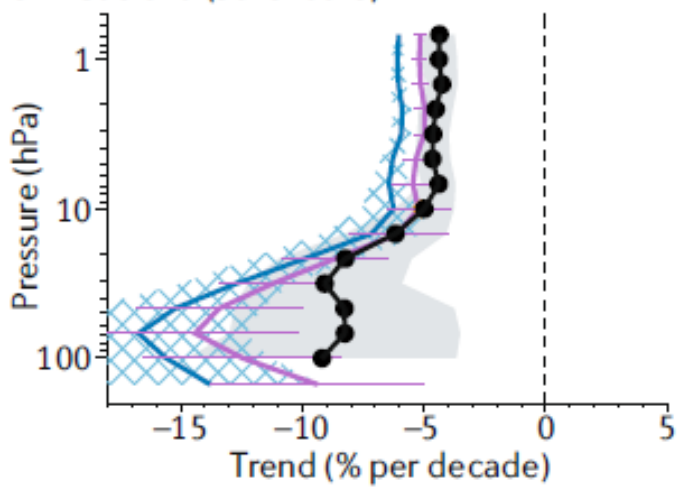

935

936

937

938

939

940

941

942

943

944

945

946

947

Figure 3. Impact of chlorinated VSLSs on stratospheric $\mathrm{HCl}$ trends. a-d| Mean $\mathrm{HCl}$ trends (2004-2017) calculated for latitude bands $60^{\circ} \mathrm{S}-60^{\circ} \mathrm{N}, 30^{\circ} \mathrm{S}-30^{\circ} \mathrm{N}, 30^{\circ} \mathrm{N}-60^{\circ} \mathrm{N}$, and $30^{\circ} \mathrm{S}-60^{\circ} \mathrm{S}$. Modelled $\mathrm{HCl}$ trends $\left(\%\right.$ decade $^{-1}$ ) with and without very short-lived substances (VSLSs) are from the TOMCAT 3-D chemical transport mode ${ }^{95}$. For the long-lived chlorine source gases the model used global mean surface mixing ratios based on observations ${ }^{96}$. Observed $\mathrm{HCl}$ trends are derived from the ACE-FTS satellite instrument ${ }^{61} .2 \sigma$ trend errors denoted by horizontal bars, shading and grating. The panels show that the inclusion of VSLS increases the $\mathrm{HCl}$ trend, especially in the lower stratosphere, bringing the model into better agreement with the observations. The observed $\mathrm{HCl}$ trend is also affected by atmospheric dynamical variability, leading to a positive trend in northern mid-latitudes and tropics, compared to the expected negative trend elsewhere ${ }^{97}$. 

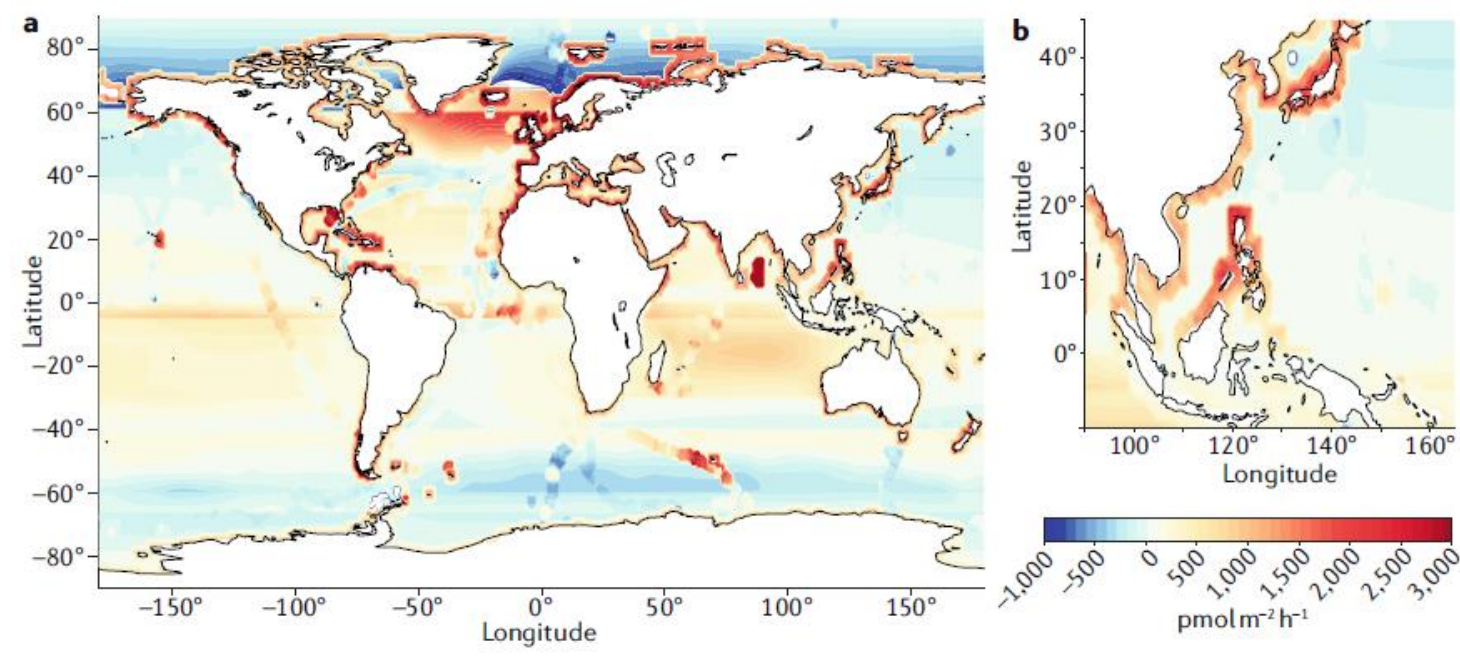

950 Figure 4. Total and anthropogenic bromoform emissions from the oceans. a,b| Global

951 bromoform $\left(\mathrm{CHBr}_{3}\right)$ emissions are shown for global and East and South-East Asia regions ${ }^{74}$

952 based on a recent update of measurement-based emission estimates ${ }^{75}$. Both panels use the

953 same colour scale. In addition to the known elevated emissions along the coastlines and in

954 upwelling regions, enhanced emissions in the tropical Indian Ocean and subtropical northern

955 Atlantic have been identified. For the west Indian Ocean, updated bromoform emissions

956 almost double and can reach the stratosphere via two transport pathways; locally through

957 convection and in the south-eastern part of the Asian monsoon anticyclone ${ }^{71}$ highlighting this

958 area as a potentially important source region. 
961

962 Figure 5. Production of chlorine-containing compounds. Chlorine $\left(\mathrm{Cl}_{2}\right)$ from chlor-alkali

963 plants is combined with methanol $\left(\mathrm{CH}_{3} \mathrm{OH}\right)$ to produce various chlorocarbons. Emissions of 964 these chemicals can occur during their production (unreported non-feedstock emissions); their 965

966

967

968

969

970

971

972

973

974

975

976

977

978

979 use as solvents; and their use as feedstock chemicals for chlorofluorocarbons (CFCs; no longer permitted), hydrochlorofluorocarbons (HCFCs), hydrofluorocarbons (HFCs), hydrofluoroolefins (HFOs) and other halogenated chemicals. Production or emissions processes are shown as arrows, with estimated amounts $\left(\mathrm{Gg} \mathrm{yr}^{-1}\right)$ for 2016 shown when available. White-filled arrows indicate use; grey-filled arrows indicate emissions. Circles are colour coded by chlorocarbon type and show either total production numbers or emissions. Grey background shading denotes emissions. Global bottom-up emissions estimates for 2016 are derived from production magnitudes, and top-down emission values for 2016 are derived from global atmospheric measurements. Note that total bottom-up emissions do not equal the sum of all contributions because many countries enforce incineration of spent solvents, especially in pharmaceutical uses, leading to lower reported emissions. This figure excludes an additional $10 \mathrm{Gg} \mathrm{yr}^{-1}$ carbon tetrachloride $\left(\mathrm{CCl}_{4}\right)$ suspected to arise from legacy emissions and from other industrial chlorination processes such as ethylene dichloride and allyl chloride production.

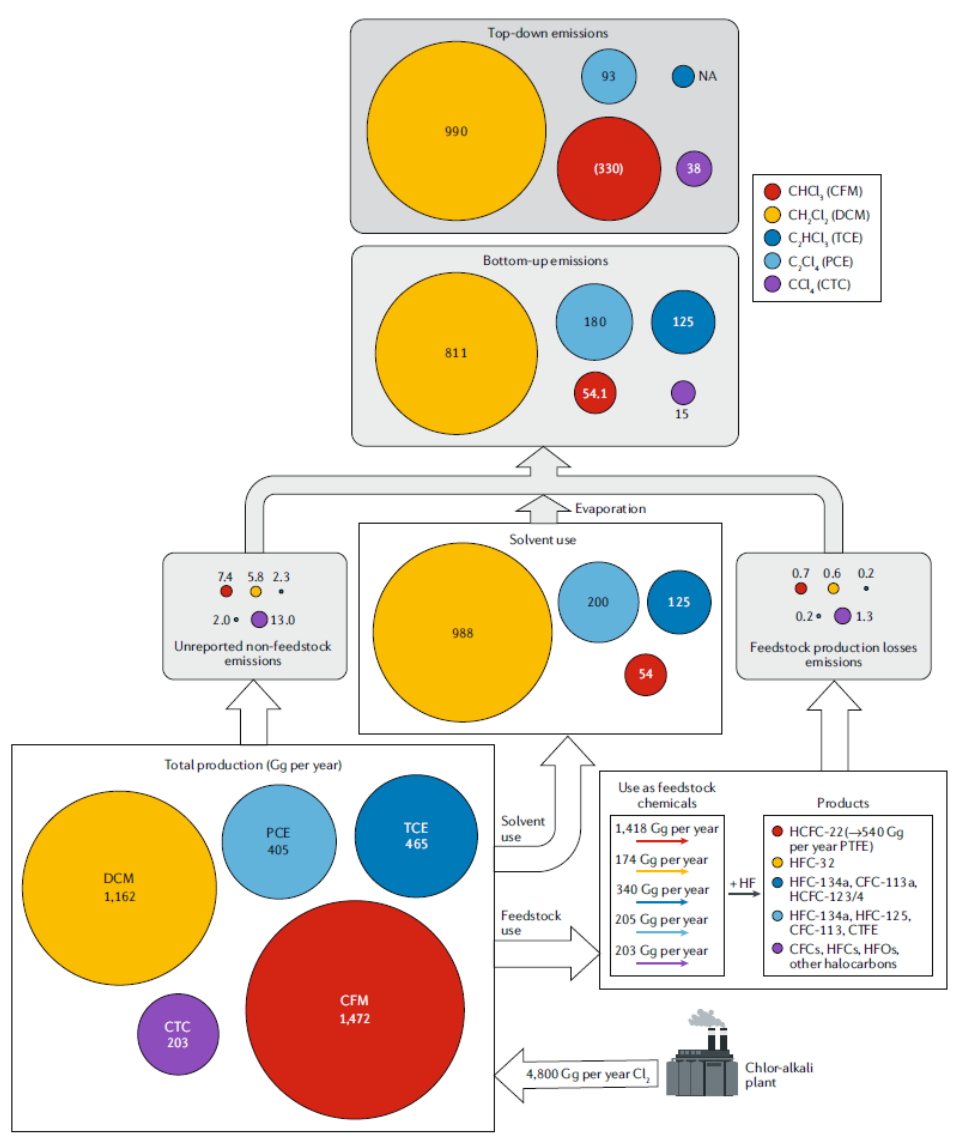



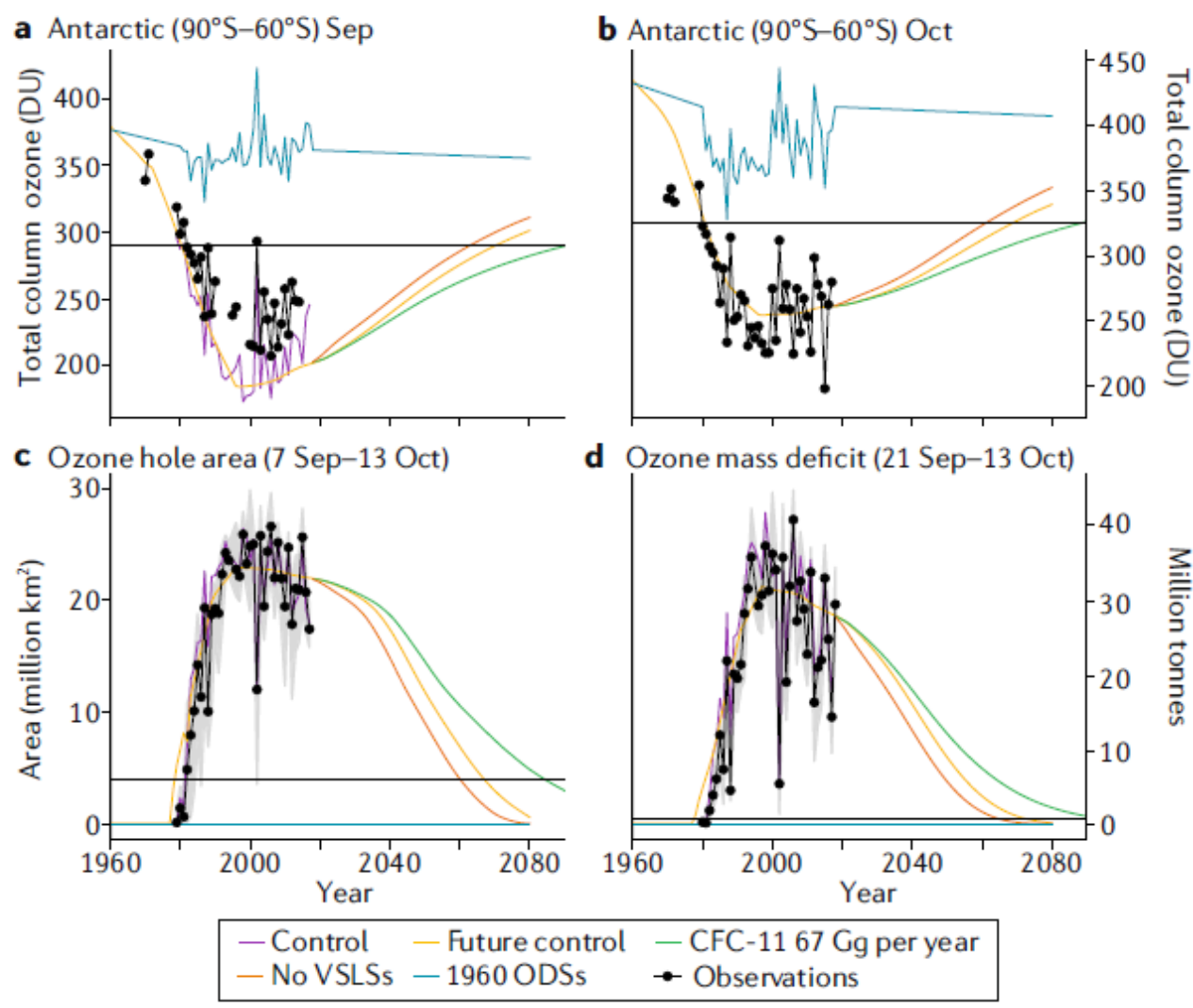

981

982 Figure 6. Antarctic ozone and metrics quantifying ozone loss as a function of additional

983 CFC-11 and VSLS emissions. a,b| Mean column ozone (in Dobson Units, DU) averaged 984 from $90^{\circ} \mathrm{S}-60^{\circ} \mathrm{S}$ for September and October from five TOMCAT 3-D model ${ }^{95,98,99}$ simulations:

985 Control (varying meteorology), future control (2000 meteorology), with constant $67 \mathrm{Gg} \mathrm{yr}^{-1}$ 986 emissions of CFC-11, with no chlorinated very short-lived substances (VSLS) and with 1960 987 levels of ozone-depleting substances (ODS), as well as NASA Solar Backscatter Ultraviolet 988 instrument observations from 1960 to 2090. c,dl Estimates of the size of the Antarctic ozone 989 hole under control, future control, $67 \mathrm{Gg} \mathrm{yr}^{-1}$ CFC-11 emissions, no VSLS, and 1960 levels of 990 ODS simulations, and observations (based on NASA Ozone Watch information) using (c) the 991 area contained within the 220 DU contour $\left(\times 10^{6} \mathrm{~km}^{2}\right)$ (averaged September 7 - October 13), 992 and (d) ozone mass deficit ( $\times 10^{6}$ tonnes) (averaged September 21 - October 13). The panels 993 show that additional emission of CFC-11 at the level assumed will delay recovery of the 994 Antarctic ozone hole, meaning a delay in the date of return to 1980 values of around 10 years. 995 Similarly, elimination of chlorinated VSLS emissions will speed up the ozone return by around 9966 years. 


\section{Glossary}

999

1000 Bank

1001

1002 Controlled

1003

1004 Fluorination

1005

1006 Lifetime

1007

1008 Non-emissive

1009

1010

1011

1012 Ozone depletion potential (ODP) Relative amount of ozone loss caused by emission of 1013

1014 Stratosphere

1015 Troposphere

1016 Uncontrolled

1017

1018 1019

Reservoir of produced ODSs stored in equipment or materials and not yet released to atmosphere.

ODS included in the Montreal Protocol for limits on consumption and production

Reaction of a feedstock with a fluorine-containing compound to produce a required substance.

Measure of the removal rate (e-folding time) of emitted species by atmospheric processes.

Application that does not lead to the immediate and direct emission of ODS.

Ozone-depleting substance (ODS) A man-made gas that causes ozone depletion once it reaches the stratosphere. $1 \mathrm{~kg}$ of a substance compared to emission of $1 \mathrm{~kg}$ of CFC-11.

Layer of atmosphere (approximately $15-50 \mathrm{~km}$ ).

Layer of atmosphere (surface to approximately $15 \mathrm{~km}$ ).

ODS not included in Montreal Protocol for limits on production and consumption.

Very short-lived substance (VSLS) Substance with an atmospheric lifetime of $<0.5$ year. 